\title{
Nota
}

\section{PRIMERA COLECCIÓN DE Pinnasa volubilis (Loasaceae) EN EL PARQUE NACIONAL LANÍN}

\author{
Medina, Andrea Alejandra ${ }^{1}$ y Torres, Leandro Ezequiel ${ }^{1}$ \\ ${ }^{1}$ Universidad Nacional del Comahue, Asentamiento Universitario \\ San Martín de los Andes \\ @ andrepampa@yahoo.com.ar
}

Recibido 08/04/2021 Aceptado $27 / 04 / 2021$

\section{RESUMEN}

En esta nota se reporta la primera colección de Pinnasa volubilis en el Parque Nacional Lanín, especie citada por primera vez para Argentina en 2019 en el centro norte de la provincia de Neuquén.

PALABRAS CLAVE: Flora; Parque Nacional Lanín; Loasaceae.

AвSTRACt. First collection of Pinnasa volubilis (Loasaceae) in Lanín National Park. In this note the first collection of Pinnasa volubilis in the Lanín National Park is reported, a species cited for the first time for Argentina in 2019 in the north-central province of Neuquén.

KEY WoRdS: Flora; Lanín National Park; Loasaceae.

\section{INTRODUCCIÓN}

En la actualidad Pinnasa comprende cuatro especies distribuidas en zonas cordilleranas y esteparias del sur de Argentina y Chile. En nuestro país se distribuyen desde las provincias de Mendoza a Santa Cruz: P. pinnatifida (Gillies ex Arn.) Weigend \& R.H. Acuña y P. nana (Phil.) Weigend \& R.H. Acuña en la Provincia Fitogeográfica Altoandina, $P$. bergii (Hieron.) Weigend \& R.H. Acuña en la Patagónica y $P$. volubilis (Dombey ex Juss.) Weigend \& R.H. Acuña en la Subantártica (Cabrera, 1976). Esta última especie se distribuye en Chile desde la Región de Valparaíso a la Región de Los Ríos y ha sido recientemente citada para Argentina en una zona disturbada de bosques de ñire (Nothofagus antarctica) a $1800 \mathrm{msnm}$ en el Cerro Caviahue, en el centro oeste de la provincia de Neuquén. El objetivo de esta nota es reportar el hallazgo de ejemplares de $P$. volubilis en cercanías a la localidad de San Martín de los Andes, provincia de Neuquén, en

Cómo citar este trabajo:

Medina, A. A. y Torres, L. E. (2021). Primera colección de Pinnasa volubilis (Loasaceae) en el Parque Nacional Lanín. Semiárida, 31(2), 71-73. tierras de jurisdicción del Parque Nacional Lanín (PNL) con el fin de aportar información sobre su distribución e incluirla en el listado de especies de flora nativa del citado Parque Nacional.

\section{MATERIALes y Métodos}

Los ejemplares (seis) fueron encontrados en un ambiente disturbado de bosque mixto de ñire ( $N$. antarctica) y ciprés de la cordillera (Austrocedrus chilensis), en una ladera con pendiente pronunciada de exposición norte, $40^{\circ}$ 6' 50,56" S, 71²0' 15,29" O, 990 msnm (Figura $1)$.

Fitogeograficamente el área pertenece al Distrito Caducifolio de la Provincia Subantártica (Cabrera, 1976). El área es jurisdicción del Parque Nacional Lanín (PNL) de la Administración de Parques Nacionales, no contando la institución con la presencia de la especie en sus listados de flora. Es importante que los Parques Nacionales enriquezcan sus listados de flora en pos de sus trabajos de conservación y manejo de las áreas naturales. Los ejemplares fueron fotografiados y dos de 

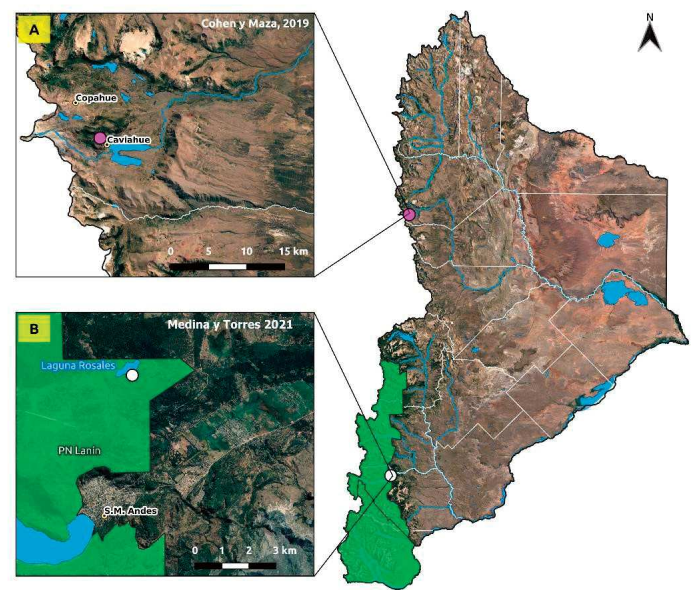

Figura 1. Mapa de la provincia de Neuquén con la ubicación del Parque Nacional Lanín y sitios de hallazgo de Pinnasa volubilis por Cohen y Maza, 2019 (A) y Medina y Torres, 2021 (B).Elaboración: Romina González Musso.

Figure 1. Map of the Neuquén province with the Lanín National Park location and the discovery sites of Pinnasa volubilis by Cohen and Maza, 2019 (A) and Medina and Torres, 2021 (B). Elaboration: Romina González Musso.

ellos colectados y conservados en el herbario del Asentamiento Universitario San Martín de los Andes de la Universidad Nacional del Comahue para su correcta determinación.

\section{Resultados}

Con la utilización de la clave para determinar las especies del género Pinnasa presentes en Argentina (Cohen y Maza, 2019) se concluyó que del material colectado corresponde a Pinnasa volubilis (Figura 2), especie recientemente citada para Argentina por dichos autores.

De las especies de Pinnasa presentes en Argentina según Cohen y Maza (2019) solo P. nana y P. bergii se encuentran a la fecha incluidas en el listado de flora del PNL, aunque con sus nombres anteriores (Loasa nana y L. bergii). P. pinnatifida está reportada para ambientes Altoandinos de latitudes menores al límite septentrional del PNL (Anton y Zuoaga, 2021). P. volubilis acaba de ser reportada por los autores del presente trabajo para su inclusión en el listado de flora del PNL.

Con este reporte serían al menos tres las especies de plantas enredaderas del género Pinnasa presentes en el Parque Nacional Lanín:

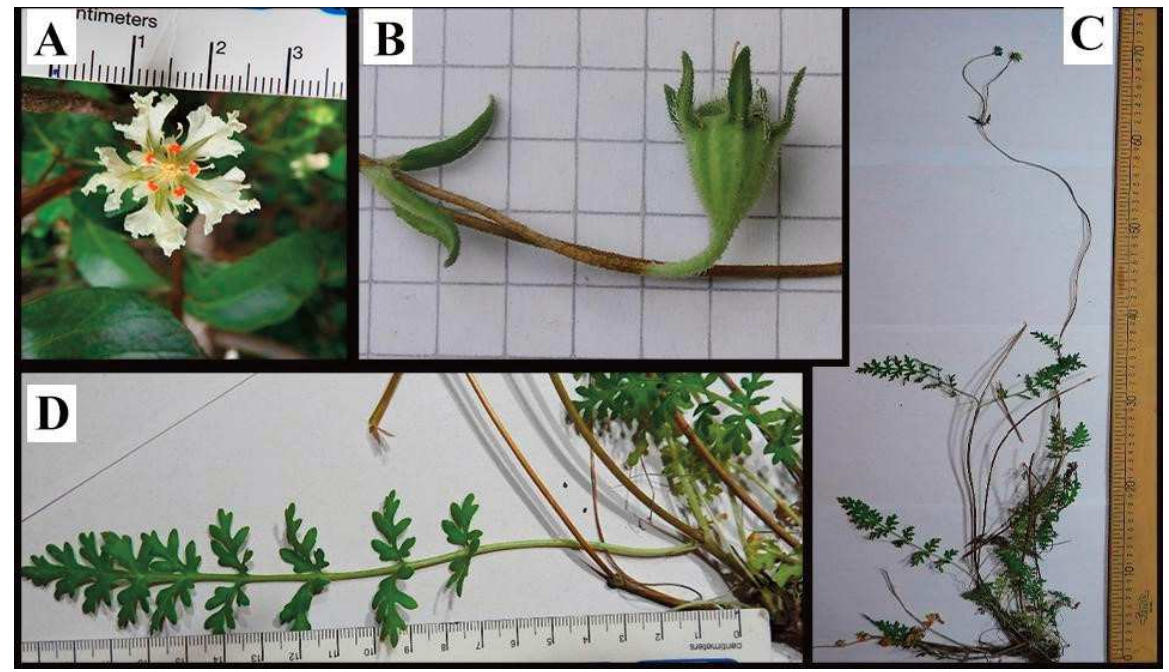

Figura 2. Fotografías de ejemplar de Pinnasa volubilis coleccionado, A) flor, B) fruto, C) planta completa y D) hoja. Imagenes: Alicia Rambeaud Rendón.

Figure 2. Photographs of a collected Pinnasa volubilis specimen, A) flower, B) fruit, C) complete plant and D) leaf. Images: Alicia Rambeaud Rendón. 
Primera colección de Pinnasa volubilis (Loasaceae) en el parque Nacional Lanín

P. volubilis, $P$. bergi y $P$. argentina Urb. \&Gilg (especie que aun debe ser trasferida a Pinnasa) (Cohen y Maza, 2019).

Pinnasa volubilis se diferencia fácilmente de $P$. bergii y de $P$. argentina por presentar flores de corola blanca. Si no se encuentran en período de floración $P$. argentina puede confundirse con $P$. volubilis, pero la primera presenta hojas pinnatipartidas mientras que la segunda tiene hojas bipinnatipartidas. Además las hojas de $P$. volubilis poseen pecíolos pronunciadamente envolventes en comparación con las otras dos especies. También es interesante apuntar que $P$. volubilis se desarrolla en ambientes boscosos mientras que las otras dos especies crecen en general en ambientes esteparios.

\section{BiBliografíA}

Anton, A. M. y Zuloaga, F. O. (directores), Flora Argentina. Fecha de consulta 15/03/2021. http://www.floraargentina.edu.ar

Cabrera, A. L. (1976). Regiones fitogeográficas de la Argentina. Enciclopedia Argentina de Agricultura y Jardinería. Tomo II. Buenos Aires, Argentina. 85 pp.

Cohen, D. H. y Maza, A. (2019). The first collection of Pinnasa volubilis (Loasaceae) for the Flora of Argentina. Darwiniana, 7(2), 330-334. 